\title{
HISTOCHEMICAL INVESTIGATION OF THE ESOPHAGUS OF THE WILD BRONZE TURKEY (MELEAGRIS GALLOPAVO)
}

\author{
D. Yovchev ${ }^{*}$, G. Penchev \\ Department of Veterinary Anatomy, Histology and Embryology, Faculty of Veterinary \\ Medicine, Trakia University, Stara Zagora, Bulgaria
}

\begin{abstract}
The aim of the present study was to investigate the thoracic part of the esophagus in the bronze turkey, using Masson's trichrome stain and Alcian blue-PAS staining. Thirty-six clinically healthy bronze turkeys (eighteen males and eighteen females) were studied. The groups of the birds were at age 1, 7, 14, 28, 35 and 49 days. Each group consisted of three male and three female birds. The histological features of the organ were similar in the studied groups. It consisted of tunica mucosa, tunica submucosa, tunica muscularis, and tunica serosa. There were no specifics in the organ regarding the sex and the age of the birds. The esophageal glands in all of the studied groups, demonstrated intensive PAS and AB reaction, because of the mucous, produced by the epithelial glandular cells. Lamina propria exhibited a weak PAS reaction, visible in all ages, either in males, either in females.
\end{abstract}

Key words: bronze turkey, esophagus, histochemistry, glands

\section{INTRODUCTION}

The avian esophagus is a wide tube organ. It has three parts: cervical, crop and thoracic. This organ is with thin walls, whose cervical part is situated on the right side of the neck $(1,2)$.

The esophagus of the common wood pigeon and barn owl is composed of mucosa, submucosa, muscularis externa and serosa. The epithelium of the mucosa in the esophageal glands of the cervical and thoracic part of the common wood pigeon and barn owl has differences. It is keratinized stratified squamous epithelium in the common wood pigeon while in the barn owl, it is non-keratinized stratified squamous epithelium. The esophageal glands are tubuloalveolar in the barn owl. There are no glands in the common wood pigeon. Lamina propria of the inner folds of the esophagus in the barn owl contained many compound tubualveolar acin-like esophageal glands. The submucosa of the esophagus in the common wood pigeon contained less number of compound alveolar flask-like esophageal glands (2).

The morphological specifics of the esophagus

\footnotetext{
*Correspondence to: David Yovchev, Department of Veterinary Anatomy, Histology and Embryology, Faculty of Veterinary Medicine, Trakia University, Stara Zagora, Bulgaria; e-mail: davidgospodinovyovchev@gmail.com
}

in broiler chickens have been studied in order to determine the impact of the sex, age and different esophageal parts on the histological specifics of the organ. There are no age differences regarding the layer composition of the esophagus. In all age groups the organ is composed of tunica mucosa, tunica submucosa, tunica muscularis as tunica adventitia is found in the cervical part and tunica serosa in the thoracic part. The glands were mucosal, simple branched and more numerous in the thoracic part of the organ, located around in an esophageal crypt (3).

The glands in the esophagus of the GreyBacked shrike are mucous. The glands' lumens exhibited intensive positive periodic AcidSchiff and Alcian blue reaction. In the lamina propria, there are superficial and profound lamellas. The simple tubular glands were in the superficial lamella and the complex tubular glands were found in the profound lamella (4).

In previous studies, some authors (5) carried out histological study of turkey's esophagus haematoxylin/eosin in order to give data for the development of the tissue layers of turkey esophageal wall, during post- hatch development. 
Some investigations are focused on macro and micromorphometrical and histological analysis of the intestinal tract of the turkey, Japan quail, wild quail, ducks, quails and broiler chickens (6-11). The published information for turkey's esophagus is insufficient.

The scarce data for the histochemical specifics of the turkey's esophagus and organ's glands using Masson's trichrome stain and Alcian blue-PAS staining was the motivation for the present study.

\section{MATERIALS AND METHODS}

Tissue samples from the thoracic part of the esophagus of thirty-six clinically healthy bronze turkeys (eighteen males and eighteen females) were studied. Each group consisted of three male and three female birds. The animals were used in the scientific project "Histological and histometrical investigation of the small intestines of the bronze turkey (Meleagris meleagris gallopovo) in age aspect". The groups of the birds were at age 1, $7,14,28,35$ and 49 days. The study was conducted in strict compliance with the University's ethical guidelines.

After removing the whole esophagus, samples were taken from the thoracic part of the organ. The samples were fixed in $10 \%$ neutral buffered formalin solution for 24 hours. They were dehydrated with alcohol and embedded in paraffin wax. The thickness of the cuts was $5 \mu \mathrm{m}$. The methods were Masson's trichrome stain and Alcian blue (pH 2.5)-PAS staining. The tissue samples were observed by light microscope - VDN-200M
(LUMENLAB, China). The results were snapped by digital micro camera CMOS.

\section{RESULTS}

The histological features of the thoracic part of the esophagus in the bronze turkeys were similar in the studied groups. It consisted of tunica mucosa, tunica submucosa, tunica muscularis and tunica serosa. There were no specifics in the organ regarding the sex and the age of the birds.

Tunica mucosa was composed of longitudinal folds. The epithelium of the folds was keratinized stratified squamous epithelium. Lamina propria was composed of loose connective tissue. It had compound tubular mucous glands, surrounding the esophageal crypts. There were several lymph nodules. The number of the esophageal glands varied from fifteen to twenty. Lamina muscularis mucosae was continuous and well developed, supported by smooth muscle tissue.

Tunica submucosa was composed of loose connective tissue. Tunica muscularis was constructed by smooth muscle, arranged in two sublayers - the inner was circular and thinner and the outer was longitudinal and wider. Tunica serosa was composed by loose connective tissue covered by mesothelium (Figure 1 and Figure 2).

The esophageal glands in all of the studied groups, demonstrated intensive PAS and $\mathrm{AB}$ reaction, because of the mucous, produced by the epithelial glandular cells. Lamina propria exhibited a weak PAS reaction, visible in all ages, either in males, either in females (Figure 2).

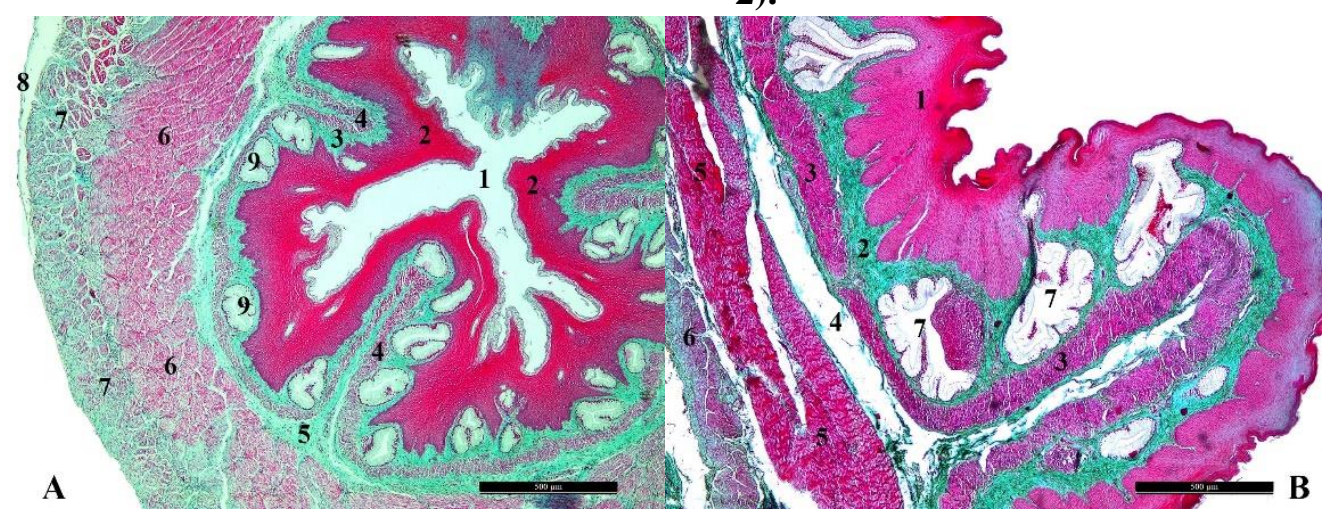

Figure 1. Photomicrograph of turkey esophagus. A - at the $7^{\text {th }}$ day of age (line $\left.-500 \mu \mathrm{m}\right)$. (1) lumen; (2) keratinized stratified squamous epithelium; (3) lamina propria; (4) lamina muscularis; (5) tunica submucosa; (6) inner circular layer of tunica muscularis; (7) outer longitudinal layer of tunica muscularis; (8) tunica serosa; (9) esophageal glands. B - at the $35^{\text {th }}$ day of age (line $-500 \mu \mathrm{m}$ ). (1) keratinized stratified squamous epithelium; (2) lamina propria; (3) lamina muscularis; (4) tunica submucosa; (5) inner circular layer of tunica muscularis; (6) outer longitudinal layer of tunica muscularis; (7) esophageal glands. Masson's trichrome stain. 


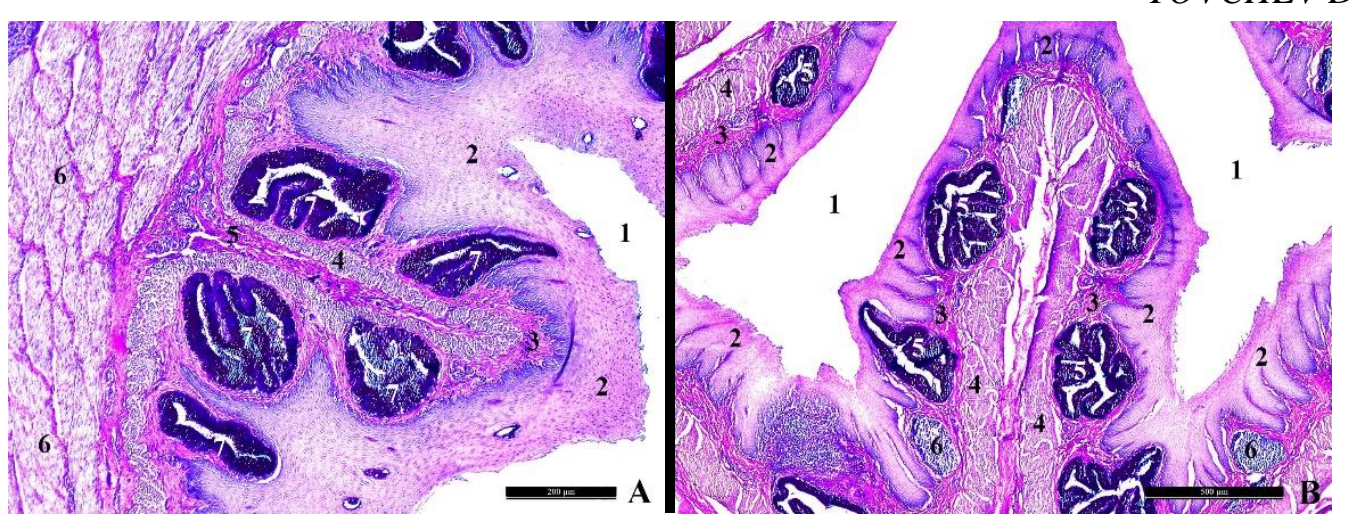

Figure 2. Photomicrograph of turkey esophagus. A - at the 7th day of age (line - $200 \mu \mathrm{m})$. (1) lumen; (2) keratinized stratified squamous epithelium; (3) lamina propria; (4) lamina muscularis; (5) tunica submисоsa; (6) inner circular layer of tunica muscularis; (7) esophageal glands. B - at the $35^{\text {th }}$ day of age (line $\left.-500 \mu \mathrm{m}\right)$. (1) lumen; (2) keratinized stratified squamous epithelium; (3) lamina propria; (4) lamina muscularis; (5) esophageal glands; (6) lymph nodules. Alcian blue - PAS staining.

\section{DISCUSSION}

The results of the present study described the bronze turkey's esophagus as a tube organ, composed of three parts. Our investigation was focused on the thoracic part of the esophagus of the bronze turkey. Therefore, we added the attitude of some authors for the subdivision of the esophagus organ and its morphological specifics as a tube organ $(1,2)$.

Our data from Masson's trichrome stain and Alcian blue - PAS staining presented that the bronze turkeys' esophagus in its thoracic part is composed of four layers. At the same time, we give a description of the epithelium in mucosa as stratified squamous keratinized. The results, that concern the type of the epithelium correspond the data for the common wood pigeon and differ to the theory for the same tissue in the barn owl. In addition, we defined the esophageal glands as compound tubular glands, which contradict to the theory for the same glands in the common wood pigeon and the barn owl (2).

In our study we did not find age differences regarding the layer composition of the esophagus. We presented data which proved well developed tunica mucosa, tunica submucosa, tunica muscularis and tunica serosa in the thoracic part of the organ. We described the esophageal glands as compound tubular glands, situated close to the esophageal crypt. Our theory for histological structure of the bronze turkey's esophagus confirm the data for the same organ in the broiler chickens and meantime it differs to the published data for the type of the esophageal glands (3).
In our investigation we identified the high intensity of the periodic Acid-Schiff and Alcian blue reaction in the esophageal glands. That was achieved because of the secreted mucous from the glandular epithelial cells. In spite of the fact that the studied glands are compound tubular in the bronze turkey, compared to the same in the Grey-Backed Shrike (simple tubular) (4), according to us, the secretion of mucous provoked the intensity of the histochemical reaction.

\section{CONCLUSIONS}

The histological features of the thoracic part of the esophagus in the bronze turkeys were similar in the studied groups. There were no specifics in the organ regarding the sex and the age of the birds.

The folds in tunica mucosa were longitudinal as the epithelium was keratinized stratified squamous. The glands in lamina propria were compound tubular mucous, surrounding the esophageal crypts.

\section{REFERENCES}

1. King, A. S., Mclelland, J., Birds. Their structure and Function. 2nd edn, Bailliere Tindall, London, 1984.

2. Al-Juboory, R. W., Hussein, A. M. D. and AlArajy, A. S., Comparative anatomical, histolo gical and histochemical studies of the oesophagus in two different Iraqi birds (Columba palumbus and Tyto alba). International Journal of Advanced Research in Biological Sciences, 2: 188-199, 2015.

3. Mobini, B., The effect of age, sex and region on histological structures of the esophagus in broiler chickens. Veterinarija Ir Zootechnika, 66: 46-49, 2014. 
4. Zhu, L. Histological study of the oesophagus and stomach in grey-backed shrike (Lanius tephronotus). International Journal of Morphology, 33: 459-464, 2015.

5. Yovchev, D. G., Georgiev G. P. and Dimitrov, D. S., Micrometrical study of the oesophageal wall of the wild bronze turkey (Meleagris gallopavo). Bulgarian Journal of Veterinary Medicine, 20: 76-79, 2017.

6. Mihaylov, R., Comparative investigations of the morphological features of the intestinal canal of the Japan quail (Coturnix Japonica T. \& Sch.) and wild quail (Coturnix coturnix L.). Dissertation, Trakia University, Stara Zagora, Bulgaria, 2006.

7. Mihaylov, R. and Dimitrov, R., Comparative weight and metric traits of intestines in ducks, quails and broiler chickens. Journal of Animal Science, 47: 31-38, 2010.

8. Mihaylov, R., Dimitrov, R., and Yordanova, $\quad$ V., $\quad$ Comparative electronmicroscopical study of the enterocytes of the duodenum of the
YOVCHEV D., et al.

Japanese quail (Coturnix japonica) and the wild type (Coturnix coturnix). Agricultural Science \& Technology, 4: 328-331, 2012.

9. Mihaylov, R. and Dimitrov, R., Comparative weight and metric traits of intestines in Japanese quails (Coturnix coturnix Japonica), common quails (Coturnix coturnix, Lineus, 1758) and their hybrids. International Journal in Physical \& Applied Sciences, 2: 33-38, 2015.

10. Yovchev, D., Dimitrov, D. and Penchev, G., Age weight and morphometrical parameters of the bronze turkey's (Meleagris meleagris gallopavo) intestines. Bulgarian Journal of Agricultural Science, 19: 615-618, 2013.

11. Yovchev, D., Penchev G., Dimitrov, D. and Stamatova-Yovcheva,

K., Micromorphometric study of the small intestines in different post-hatch periods in bronze turkey (Meleagris meleagris gallopavo). Bulgarian Journal of Agricultural Science, 25: 552-557, 2019. 